\title{
Anti-inflammatory and hepatoprotective potentials of the aerial parts of Silene villosa Caryophyllaceae methanol extract in rats
}

\author{
Hasan S Yusufoglu ${ }^{1 *}$, Gamal A Soliman ${ }^{2,3}$, Ahmed I Foudah ${ }^{1}$, Maged S Abdel- \\ kader $^{1,4}$, Aftab Alam ${ }^{1}$, Mohammad Ayman Salkini ${ }^{1}$ \\ ${ }^{1}$ Department of Pharmacognosy, ${ }^{2}$ Department of Pharmacology, College of Pharmacy, Prince Sattam bin Abdulaziz University, \\ Al-Kharj, Kingdom of Saudi Arabia, ${ }^{3}$ Department of Pharmacology, College of Veterinary Medicine, Cairo University, \\ ${ }^{4}$ Department of Pharmacognosy, College of Pharmacy, Alexandria University, Egypt
}

${ }^{*}$ For correspondence: Email: hasanagazar@hotmail.com, h.yusufoglu@sau.edu.sa; Tel: 00966-11-588-6012; Fax: 00966-11$588-6001$

\begin{abstract}
Purpose: To explore the anti-inflammatory and hepatoprotective potentials of Silene villosa Caryophyllaceae methanol extract in rats.

Methods: Toxicity of S. villosa extract was evaluated in rats. Inflammation was induced in rats by injection of $0.1 \mathrm{~mL}$ carrageenan $(1 \%)$ in the left hind paws. Carbon tetrachloride $\left(\mathrm{CCl}_{4}\right)$ was used to induce liver damage. Five groups of rat were used. The 1st (normal control) and 2nd (hepatotoxic) groups received the vehicle. The 3rd, 4th, and 5th groups received silymarin, 250 and $500 \mathrm{mg} / \mathrm{kg}$ of S. villosa extract, respectively, for 7 days. Liver injury was induced on the 7th day by intraperitoneal administration of $1 \mathrm{~mL} / \mathrm{kg}$ of $\mathrm{CCl}_{4}$ to rats in groups $2-5$.

Results: The results showed that $S$. villosa is safe. It significantly reduced carrageenan-induced edema compared to normal $(p<0.01)$ and standard $(p<0.01)$ groups. The extract protected $(p<0.01)$ rats against the deleterious effect of $\mathrm{CCl}_{4}$. It decreased $(p<0.01)$ the elevated serum activities of alanine aminotransferase (ALT), aspartate aminotransferase (AST), $\gamma$-glutamyl transferase $(\gamma-G T)$ and alkaline phosphatase $(A L P)$ as well as elevated serum levels of bilirubin (BRN), compared to CCl4 control rats. Reduced activities of the antioxidant enzymes were significantly increased $(p<0.01)$ in rat liver, compared with $\mathrm{CCl}_{4}$ control group. The results were confirmed by histological findings in rat liver as the extract reduced necrosis and hydropic degeneration of hepatic tissue compared to $\mathrm{CCl}_{4}$ control group. Conclusion: The results suggest that $S$. villosa possesses anti-inflammatory and hepatoprotective activities in rats, and therefore, has therapeutic potentials in humans.
\end{abstract}

Keywords: S. villosa, anti-inflammatory, carrageenan, $\mathrm{CCl}_{4}$, antioxidant, hepatotoxicity.

\begin{abstract}
This is an Open Access article that uses a funding model which does not charge readers or their institutions for access and distributed under the terms of the Creative Commons Attribution License (http://creativecommons.org/licenses/by/4.0) and the Budapest Open Access Initiative (http://www.budapestopenaccessinitiative.org/read), which permit unrestricted use, distribution, and reproduction in any medium, provided the original work is properly credited.

Tropical Journal of Pharmaceutical Research is indexed by Science Citation Index (SciSearch), Scopus, International Pharmaceutical Abstract, Chemical Abstracts, Embase, Index Copernicus, EBSCO, African Index Medicus, JournalSeek, Journal Citation Reports/Science Edition, Directory of Open Access Journals (DOAJ), African Journal Online, Bioline International, Open-J-Gate and Pharmacy Abstracts
\end{abstract}

\section{INTRODUCTION}

The liver is one of the major organs in the human body. It carries out the ordinary metabolic homeostasis of the body as well as the processes of detoxification and excretion of many compounds [1]. According to Nazeema and Brindha [2], hepatitis is the major hepatic 
disorder that accounts for high death rate. Mostly, liver damage is considered a result of exposure to ecological poisons, which are linked with metabolic dysfunctions, ranging from temporary increase of liver enzymes to lifethreatening liver cirrhosis [3].

$\mathrm{CCl}_{4}$ is widely used to induce experimental hepatotoxicity in laboratory animals [4]. The adverse effects of $\mathrm{CCl}_{4}$ are mediated by the highly reactive free trichloromethyl radical $\left(\mathrm{CCl}_{3}{ }^{\circ}\right)$. The free radical of $\mathrm{CCl}_{4}$ reacts with oxygen to generate trichloromethylperoxyl radical $\left(\mathrm{CCl}_{3} \mathrm{OO} \cdot\right)$, which in turn reacts with polyunsaturated fatty acids of the membranous system leading to oxidative injuries such as lipid peroxidation [5]. Accordingly, the free radical mediated lipid peroxidation (LPO) is one of the major mechanisms of hepatic damage by $\mathrm{CCl}_{4}$ [6].

The family, Caryophyllaceae, is widely known as gardening herbs but the medicinal importance of its members is sparsely known. Among 2,630 species of the Caryophyllaceae family, only a small fraction ( $50-90$ species) is known to have medicinal properties [7]. The ethnopharmacological studies of the Caryophyllaceae family indicate that members of this family possess anticancer, antibacterial, antifungal, antiviral, antioxidant, and antiinflammatory properties [7]. The genus Silene (family Caryophyllaceae) involves more than 700 species of annuals, perennials, and biennials [8].

Some of Silene species have been used traditionally for treatment of cold, bronchitis, inflammations, and infections or as a diuretic, emetic, analgesic, and antipyretic [9]. The roots of some species, such as $S$. kumaonensis, $S$. latifolia, $S$. conoidea, and $S$. acaulis rich in saponins, have been traditionally used as a soap substitute for washing clothes [10]. The herb; $S$. villosa grows wildly in Saudi Arabia and is well known as Terba [11]. One of the studies on wild Egyptian S. villosa suggested its immunemodulation and antioxidant effects [12]. However, information about the pharmacological activities of $S$. villosa is very little. The purpose of the current study is to explore the antiinflammatory and hepatoprotective potential of $S$. villosa extract in rats.

\section{EXPERIMENTAL}

\section{Plant material}

The herb of $S$. villosa was collected in early March 2016 from Al-shadeedah village - $9 \mathrm{~km}$ north of Al-Kharj region of Saudi Arabia. The collected plant was authenticated by taxonomist Dr. M. Atiqur Rahman, Pharmacy College, Medicinal, Aromatic and Poisonous Plants Research Center, King Saud University, Riyadh. A voucher specimen (no. PSAU - $\mathrm{CPH}$ - 2 2016) is maintained in the herbarium of Pharmacy College, Prince Sattam bin Abdulaziz University Al-Kharj, Kingdom of Saudi Arabia. The shed dried herbs $(500 \mathrm{~g})$ were coarsely powdered and macerated in 3 liters of Methanol for $72 \mathrm{~h}$ using percolation method. The methanol was then removed at $50{ }^{\circ} \mathrm{C}$ under reduced pressure in a rotatory evaporator.

\section{Animals}

Adult male Wistar albino rats $(180-200 \mathrm{~g})$ were obtained from Lab Animal Care Unit at Pharmacy College, Prince Sattam bin Abdulaziz University, Al-Kharj, KSA, and were used for the experiments. Rats were preserved under standard situations of temperature $\left(23 \pm 1.0^{\circ} \mathrm{C}\right)$ and $12 \mathrm{~h}$ light/12 $\mathrm{h}$ dark cycle. Rats were fed with standard diet and water ad libitum. The study protocol was approved by the Institutional Animal Ethics Committee, Pharmacy College, Prince Sattam Bin Abdulaziz University, Al-Kharj, Kingdom of Saudi Arabia (protocol no. PHARM02-5-2016), and followed the Guide for the Care and Use of Laboratory Animals [13].

\section{Acute toxicity study}

Acute toxicity of $S$. villosa extract was studied following the guidelines of the Organization for Economic Co-operation and Development [14]. Twelve rats were fasted overnight and divided to 2 equal groups. Animals of the first group received a single oral dose of $S$. villosa extract $(5000 \mathrm{mg} / \mathrm{kg})$. Rats of the second group received an oral dose of the vehicle (3\% v/v Tween 80 in distilled water) and kept as control. Rats were observed for the signs of toxicity and/or deaths for $30 \mathrm{~min}$ and periodically during $24 \mathrm{~h}$, then every $24 \mathrm{~h}$ for a period of 14 days.

\section{Anti-inflammatory activity}

The anti-inflammatory potential of $S$. villosa extract was estimated in rats according to Winter et al [15]. Four groups of animals $(n=6)$ were used. Groups I (normal control) and II (reference) orally received the vehicle $(2 \mathrm{~mL} / \mathrm{kg})$ and phenylbutazone (PBZ) at $5 \mathrm{mg} / \mathrm{kg}$, respectively. Groups III and IV received $S$. villosa extract at 250 and $500 \mathrm{mg} / \mathrm{kg}$, respectively by oral route. One hour later, the rats were subcutaneously injected with $100 \mu \mathrm{L}$ of $1 \%$ suspension of carrageenan (Sigma chemical co, St. Louis MO, USA) in normal saline into the plantar side of the 
left hind paw. The volume of erach paw was estimated directly after carrageenan injection $(0$ h) and then after $3 \mathrm{~h}$ using a plethysmograph apparatus.

\section{Hepatoprotective activity}

The hepatoprotective activity of $S$. villosa extract was evaluated in adult rats by using $\mathrm{CCl}_{4}$ as a hepatotoxic agent [4]. Five groups of male rats were used $(n=6)$. Animals of the 1 st and $2 n d$ (normal and hepatotoxic controls, respectively) groups administered the vehicle (Tween $80,3 \%$ in distilled water) at $2 \mathrm{~mL} / \mathrm{kg}$. The $3 \mathrm{rd}$ group kept as reference and was prophylactically treated with silymarin at $50 \mathrm{mg} / \mathrm{kg}$. Rats of the 4th and 5 th groups administered $S$. villosa extract at doses of 250 and $500 \mathrm{mg} / \mathrm{kg}$, respectively. The vehicle (Tween 80 ), silymarin and $S$. villosa extract were dosed orally for 7 days. On the 7 th day, hepatotoxicity was induced in rats of groups II - V using $1 \mathrm{~mL} / \mathrm{kg}$ of $\mathrm{CCl}_{4}$ (50\% solution in olive oil) by intraperitoneal route [4], while rats of Group I were injected with an equal volume of olive oil.

\section{Autopsy schedule}

After $48 \mathrm{~h}$ of $\mathrm{CCl}_{4}$-induced hepatotoxicity, blood samples $(3 \mathrm{~mL})$ were obtained from all rats by puncturing their retro-orbital plexus under mild ketamine anesthesia. Serum was separated following centrifugation of blood samples at 3000 rpm for 15 min. Liver of each rat was removed, washed with cold normal saline and blotted. Half of each liver was frozen (at $-70{ }^{\circ} \mathrm{C}$ ) for biochemical analysis and the remaining half was fixed in buffered formalin $10 \%$ for histological study.

\section{Assessment of biochemical parameters}

The serum activities of liver marker enzymes (ALT, AST, Y-GT, and ALP) and serum levels of BRN, total protein (TP), and albumin (ALB) were evaluated according to the instructor manual of commercially available kits from Sigma-Aldrich (United States of America).

\section{Determination of antioxidant status}

A portion of liver was homogenized in ice-cold $1.15 \% \mathrm{w} / \mathrm{v} \mathrm{KCl}$ in a Potter Elvehjem Teflonglass homogenizer for one minute to obtain a 10 $\% \mathrm{w} / \mathrm{v}$ liver homogenate. The activities of the antioxidant enzymes like superoxide dismutase (SOD), catalase (CAT), and glutathione peroxidase (GPx) and the levels of glutathione (GSH) and malondialdehyde (MDA) were estimated in liver tissue homogenates of rats according to the instructor manual of commercially available kits from Sigma-Aldrich (United States of America).

\section{Histopathological examination}

Liver specimens were fixed in buffered formalin $10 \%$, processed routinely, and embedded in paraffin. $5 \mu \mathrm{m}$ thick sections were prepared and stained with hematoxylin and eosin (H\&E) dye for microscopic investigation. The stained sections were examined and photographed under a light microscope.

\section{Statistical analysis.}

Data are expressed as the mean \pm standard error $(n=6)$. Results were analyzed by one-way analysis of variance (ANOVA) followed by Dunnett's test using SPSS ver. 14.0. $P<0.05$ and $p<0.01$ were considered significant, respectively.

\section{RESULTS}

\section{Acute toxicity}

The result indicates that $S$. villosa extract has a high safety profile. No mortalities were observed in rats following oral dosing of the extract at 5000 $\mathrm{mg} / \mathrm{kg}$ and none of them showed signs of toxicity. Hence, doses of 250 and $500 \mathrm{mg} / \mathrm{kg}$ of S. villosa extract were selected for further investigation.

\section{Anti-inflammatory activity}

The anti-inflammatory activity of $S$. villosa is presented in Table 1 and Figure 1. Subcutaneous injection of carrageenan $(100 \mu \mathrm{L}$ of $1 \%$ suspension) created an inflammatory edema in the foot pad of rat hind paw. At the 3rd hour following carrageenan injection, the paw swelling was increased by $178.09 \%$ compared to the initial volume. As shown in Table 1, the volume of swellings induced by carrageenin in hind paws of rats $(1.78 \mathrm{~mL})$ were markedly reduced $(p<0.05)$ by 250 and $500 \mathrm{mg} / \mathrm{kg}$ of $S$. villosa extract, dose-dependently $(1.14 \mathrm{~mL}$ and $0.95 \mathrm{~mL}$, respectively) and by PBZ $(0.60 \mathrm{~mL})$.

\section{Hepatoprotective activity}

Tables 2 and 3 show the effect of $S$. villosa extract on some liver function biomarkers of $\mathrm{CCl}_{4}$-exposed rats. Exposure of rats to $\mathrm{CCl}_{4}$ was observed to cause significant increase $(p<0.01)$ in the serum activities of ALT, AST, $Y$-GT, and ALP in comparison with normal rats. The results showed that $S$. villosa extract at 250 and $500 \mathrm{mg} / \mathrm{kg}$ were able to retain the serum liver 
function biomarkers of $\mathrm{CCl}_{4}$-exposed rats toward the normal levels. The higher dose of the extract $(500 \mathrm{mg} / \mathrm{kg})$ displayed the highest suppression $(p$ $<0.01$ ) in percentage of serum ALT, AST, $\mathrm{Y}$-GT and ALP, when compared to $\mathrm{CCl}_{4}$ control group. Silymarin showed more significant and better inhibition.

In addition, $\mathrm{CCl}_{4}$-exposed rats demonstrated significant elevation $(p<0.01)$ in serum level of BRN and decrease in TP and ALB values in comparison with the normal control group. Pretreatment with $S$. villosa extract exhibited a marked reversal of BRN, TP and ALB toward their normal values (Table 3). The efficacy of the tested extract was found to be dose dependent.

Table 4 shows the effect of $S$. villosa extracts on biochemical variables indicative of liver oxidative stress in rats. The results indicated that $\mathrm{CCl}_{4}$ induced oxidative stress with a significant decrease $(p<0.01)$ in the activities of liver SOD, CAT and GPx in comparison with the normal control values. In addition, hepatic GSH showed a significant $(p<0.01)$ decrease while MDA levels significantly $(p<0.01)$ increased in $\mathrm{CCl}_{4}$ exposed rats relative to the normal group.

Pretreatment with both doses of $S$. villosa extract decreased the oxidative stress, as evidenced by increased activities of SOD $(p<0.05)$, CAT $(p<$ $0.05)$, and $\operatorname{GPx}(p<0.01)$ in liver tissues when compared with those of $\mathrm{CCl}_{4}$-exposed rats.

Table 1: Anti-inflammatory activity of $S$. villosa on carrageenan- induced paw edema

\begin{tabular}{lcccc}
\hline Group & $\begin{array}{c}\text { Dose } \\
(\mathbf{m L} / \mathbf{k g})\end{array}$ & $\mathbf{0 ~ h}$ & $\mathbf{3 ~ h}$ & $\begin{array}{c}\text { Paw volume (mL) } \\
\text { Difference } \\
\text { in } \\
\text { paw } \\
\text { volume }\end{array}$ \\
\hline Control & 0.1 & $1.05 \pm 0.05$ & $2.92 \pm 0.11$ & $1.78 \pm 0.10$ \\
PBZ & 5 & $1.04 \pm 0.04$ & $1.67 \pm 0.05$ & $0.60 \pm 0.05 \#$ \\
S. & 250 & $1.03 \pm 0.05$ & $2.21 \pm 0.12$ & $1.14 \pm 0.11 \#$ \\
$\begin{array}{l}\text { villosa } \\
\text { S. } \\
\text { villosa }\end{array}$ & 500 & $1.04 \pm 0.02$ & $2.03 \pm 0.10$ & $0.95 \pm 0.07 \#$ \\
\hline $\begin{array}{l}\text { Values are expressed as mean } \pm \text { SEM of six animals } \\
\text { in each group; \#indicate significance compared to } \\
\text { normal control group at } p<0.05 \text { (Dunnett's test) }\end{array}$
\end{tabular}

Table 2: Effect of the ethanol extract of $S$. villosa on the serum activity of liver marker enzymes in rats with $\mathrm{CCl}_{4^{-}}$ induced hepatotoxicity

\begin{tabular}{lcccc}
\hline Group & ALT (U/L) & AST (U/L) & Y-GT (U/L) & ALP (U/L) \\
\hline Normal control & $34.01 \pm 2.43 \#$ & $104.68 \pm 5.81 \#$ & $17.16 \pm 0.98 \#$ & $103.19 \pm 7.13 \#$ \\
CCl4-hepatotoxic control & $116.16 \pm 7.69 \phi$ & $284.50 \pm 15.25 \phi$ & $38.18 \pm 1.21 \phi$ & $309.45 \pm 19.54 \phi$ \\
& $(241.54 \%)$ & $(171.78 \%)$ & $(122.49 \%)$ & $(199.88 \%)$ \\
Silymarin (50 mg/kg)+CCl4 & $40.43 \pm 2.85 \#$ & $126.16 \pm 8.57 \#$ & $20.13 \pm 1.22 \#$ & $137.66 \pm 8.32^{\star} \#$ \\
& $(-65.19 \%)$ & $(-55.65 \%)$ & $(-47.27 \%)$ & $(-55.51 \%)$ \\
S. villosa (250 mg/kg)+CCl4 & $61.33 \pm 4.66 \phi \#$ & $162.5 \pm 9.95 \phi \#$ & $28.49 \pm 1.42 \phi \#$ & $188.41 \pm 14.49 \phi \#$ \\
& $(-47.20 \%)$ & $(-42.88 \%)$ & $(-25.37 \%)$ & $(-39.11 \%)$ \\
S. villosa (500 mg/kg)+CCl4 & $54.16 \pm 3.91^{*} \#$ & $148.74 \pm 9.28^{\star} \#$ & $22.64 \pm 1.85^{\star} \#$ & $167.96 \pm 12.92^{\star} \#$ \\
& $(-53.37 \%)$ & $(-47.71 \%)$ & $(-40.70 \%)$ & $(-45.72 \%)$ \\
\hline
\end{tabular}

Values are mean \pm SEM $(n=6)$, values in parenthesis indicate \% change; ${ }^{*} p<0.05$ : statistically significant from normal control (Dunnett's test); $\phi p<0.01$ : statistically significant from normal control (Dunnett's test); $p<0.05$ : Statistically significant from CCl ${ }_{4}$-hepatotoxic control (Dunnett's test; $\# p<0.01$ : statistically significant from $\mathrm{CCl}_{4}{ }^{-}$ hepatotoxic control (Dunnett's test)

Table 3: Effect of $S$. villosa extract on the serum levels of BRN, TP, and ALB in rats with $\mathrm{CCl}_{4}$-induced hepatotoxicity

\begin{tabular}{|c|c|c|c|}
\hline Group & $\begin{array}{c}\text { BRN } \\
\text { (mg/dL) }\end{array}$ & Total protein (g/dL) & $\begin{array}{c}\text { ALB } \\
\text { (g/dL) }\end{array}$ \\
\hline Normal control & $0.64 \pm 0.04 \#$ & $8.4 \pm 0.36 \#$ & $4.1 \pm 0.26 \#$ \\
\hline $\mathrm{CCl}_{4}$-hepatotoxic control & $\begin{array}{c}1.71 \pm 0.12 \phi \\
(167.18 \%)\end{array}$ & $\begin{array}{l}5.1 \pm 0.28 \phi \\
(-39.28 \%)\end{array}$ & $\begin{array}{l}2.3 \pm 0.10 \phi \\
(-43.90 \%)\end{array}$ \\
\hline Silymarin $(50 \mathrm{mg} / \mathrm{kg})+\mathrm{CCl} 4$ & $\begin{array}{c}0.80 \pm 0.07 \# \\
(-53.21 \%)\end{array}$ & $\begin{array}{c}7.8 \pm 0.40 \# \\
(52.94 \%)\end{array}$ & $\begin{array}{c}3.6 \pm 0.15 \# \\
(56.52 \%)\end{array}$ \\
\hline S. villosa $(250 \mathrm{mg} / \mathrm{kg})+\mathrm{CCl} 4$ & $\begin{array}{c}1.25 \pm 0.10 \phi \\
(-26.90 \%)\end{array}$ & $\begin{array}{c}6.5 \pm 0.37^{\star} \\
(27.45 \%)\end{array}$ & $\begin{array}{c}2.9 \pm 0.11^{*} \\
(26.08 \%)\end{array}$ \\
\hline S. villosa $(500 \mathrm{mg} / \mathrm{kg})+\mathrm{CCl} 4$ & $\begin{array}{c}1.04 \pm 0.08^{*} \# \\
(-39.18 \%)\end{array}$ & $\begin{array}{l}7.1 \pm 0.49 \\
(39.21 \%)\end{array}$ & $\begin{array}{l}3.2 \pm 0.26 \\
(39.13 \%)\end{array}$ \\
\hline
\end{tabular}

Values are mean \pm SEM $(n=6)$, values in parenthesis indicate \% change; ${ }^{*} p<0.05$ : statistically significant from normal control (Dunnett's test); $\phi p<0.01$ : statistically significant from normal control (Dunnett's test); $: p<0.05$ : Statistically significant from $\mathrm{CCl}_{4}$-hepatotoxic control (Dunnett's test; $\# p<0.01$ : statistically significant from $\mathrm{CCl}_{4}$ hepatotoxic control (Dunnett's test) 
Table 4: Effect of $S$. villosa extract on $\mathrm{CCl}_{4}$-induced oxidative stress in rats

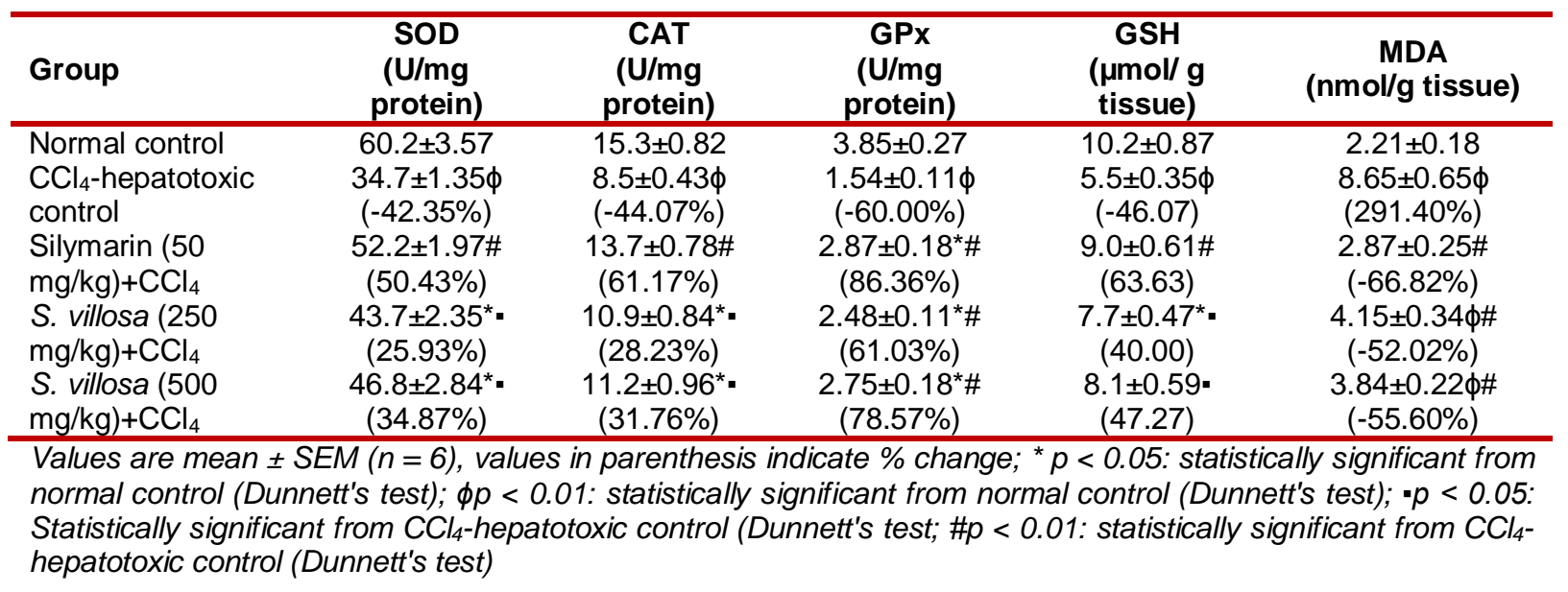

In addition, the protective action of $S$. villosa on the most potent endogenous antioxidants, GSH was estimated in liver tissue of rats (Table 4). Pretreatment with $S$. villosa (250 and $500 \mathrm{mg} / \mathrm{kg}$ ) was found to protect against GSH depletion in the liver homogenate of $\mathrm{CCl}_{4}$-exposed rats. Further, both doses reduced the increased MDA level in liver, when compared to $\mathrm{CCl}_{4}$-exposed rats.

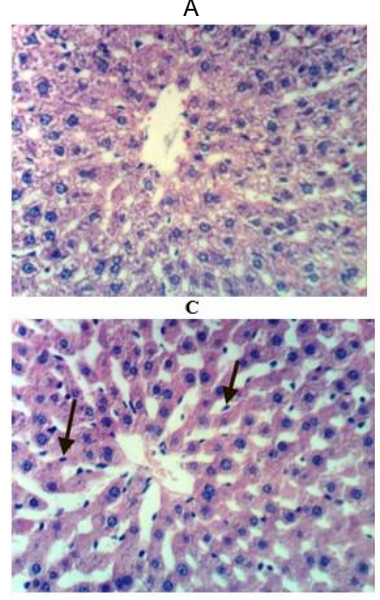

B

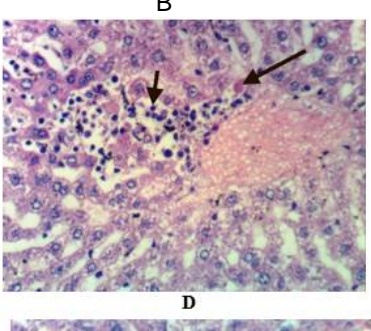

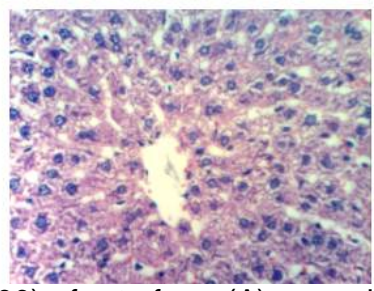

Figure 1: Liver $(H \& E X 400)$ of rats from $(A)$ normal control group, (B) $\mathrm{CCl}_{4}$-exposed group, (C) S. villosa $(250 \mathrm{mg} / \mathrm{kg})+\mathrm{CCl}_{4}$ group and (D) S. villosa (500 $\mathrm{mg} / \mathrm{kg})+\mathrm{CCl}_{4}$ group

Histological assessment of the liver of the normal rats showed the typical hepatic architecture of hepatic lobule (Figure 1A). The typical architecture of hepatic tissues was lost in rats exposed to $\mathrm{CCl}_{4}$. Liver sections of $\mathrm{CCl}_{4}$-treated rats showed severe necrosis, infiltration of neutrophils, and hydropic degeneration of the liver tissue (Figure 1B). The hepatoprotective effect of $S$. villosa was confirmed by histological inspection of the liver tissue. Pretreatment of rats with both doses of $S$. villosa reduced the severity of $\mathrm{CCl}_{4}$-induced liver intoxication. Moderate necrotic changes were noticed in hepatic tissues of animals pretreated with $S$. villosa extract at $250 \mathrm{mg} / \mathrm{kg}$ (Figure 1C). Liver tissue from rats pretreated with large dose of the extract had normal hepatic cells with mild necrotic and inflammatory changes of some hepatocytes (Figure 1D).

\section{DISCUSSION}

The results of acute toxicity study revealed that $S$. villosa extract is non-toxic. Treatment with $5000 \mathrm{mg} / \mathrm{kg}$ of $S$. villosa extract was well tolerated by rats, since there were no toxic symptoms or deaths noted during the experimental period of acute toxicity study. In this investigation, the value of the oral $L_{50}$ of $S$. villosa extract was not estimated in rats being in excess of $5000 \mathrm{mg} / \mathrm{kg}$. Generally, the lower the value of the $L D_{50}$, the higher the toxicity of the compound. Thus, the methanolic extract of $S$. villosa can be classified as non-toxic as compounds having oral $L_{50}$ value of more than $4 \mathrm{~g} / \mathrm{kg}$ are considered as being nontoxic [16].

In the current study, the potential antiinflammatory activity of $S$. villosa was investigated in rats. Carrageenan-induced paw edema in rats is one of the experimental animal model for exploring anti-inflammatory potential of extracts and other compounds [17]. Subcutaneous injection of carrageenan in the hind paw of rats induced local edema. The inflammatory response against carrageenan includes a stepwise release of vasoactive compounds such as histamine, serotonin, and bradykinin in the early phase and prostaglandins in the acute late stage [18]. These vasoactive compounds produced an increase in the permeability of blood vessels, therefore enhancing fluid accumulation in the tissues resulting in edema. 
The present results indicate that $S$. villosa suppressed the volume of edema induced by carrageenan in rat's paws in a dose-dependent manner. The ability of $S$. villosa to decrease the volume of edema proposes that it has chemical constituent(s) that may be active against inflammation.

The hepatoprotective potential of $S$. villosa extract was studied using the model of $\mathrm{CCl}_{4}$ induced hepatotoxicity in rats. Levels of liver enzymes (ALT, AST, Y-GT, and ALP) in serum have long been considered as a sensitive index of liver damage [19]. As expected, $\mathrm{CCl}_{4}$ markedly elevated the serum levels of liver marker enzymes in rats. The elevation in the levels of ALT, AST, $Y-G T$, and ALP in serum may be explained as a result of the damage of hepatic cells or alterations in their membrane permeability denoting drastic liver injury. Pretreatment with $S$. villosa extract at 250 and $500 \mathrm{mg} / \mathrm{kg}$ was able to protect against the elevation in the level of these enzymes in serum of $\mathrm{CCl}_{4}$-exposed animals. These results can be referred to as the ability of the extract to keep the membrane integrity of hepatocytes of the $\mathrm{CCl}_{4}$ exposed rats by reducing the production of the reactive metabolites of $\mathrm{CCl}_{4}$.

Serum BRN is considered as one of the most sensitive tests of liver functions. The increased level of serum $\mathrm{BRN}$ in $\mathrm{CCl}_{4}$-exposed rats indicates hepatic parenchymal damage. A possible explanation is that $\mathrm{CCl}_{4}$ exposure is known to induce the generation of reactive oxygen species that has the possibility to elicit tissue damage. This study demonstrated that $S$. villosa extract and silymarin had reduced the level of serum BRN which was elevated by $\mathrm{CCl}_{4}$ administration.

ALB is the most abundant plasma protein produced by hepatocytes. Therefore, serum levels of TP or ALB reflect the functional status of the liver [20]. It is well known that exposure to $\mathrm{CCl}_{4}$ induces a marked reduction in levels of TP and ALB in serum [21].

In the present study, a marked reduction in levels of TP and ALB was observed in serum of $\mathrm{CCl}_{4}$ control group in relation to the normal control. However, pretreatment with $S$. villosa extract showed a significant reversal of TP and ALB toward their normal levels and suggested the stabilization of endoplasmic reticulum that is responsible for protein synthesis. This assures the protective activity of $S$. villos against $\mathrm{CCl}_{4}$ hepatotoxicity.

Oxidative stress is reported to represent the main mechanism in the pathogenesis of $\mathrm{CCl}_{4}$-induced hepatotoxicity in experimental animals [22]. Oxidative stress induced by $\mathrm{CCl}_{4}$ is largely attributed to its active metabolite, trichloromethyl radical that plays a key role in producing liver damage [23]. However, cells have diverse defense processes including enzymatic and nonenzymatic antioxidants mechanisms to keep themselves against the adverse effects of free radicals. The oxidative stress gives rise to toxicity when the rate of free radicals generation outweighs the cell's ability for their removal.

The antioxidant enzymes (SOD, CAT and GPx) present the natural first line of antioxidative stress in the liver tissue. They play a substantial function in neutralizing the toxic intermediate of oxidation. SOD and CAT are the most important enzymes to remove the free radicals in vivo. SOD stimulates the dismutation of superoxide radicals $\left(\mathrm{O}_{2}^{-}\right)$into hydrogen peroxide $\left(\mathrm{H}_{2} \mathrm{O}_{2}\right)$ and molecular oxygen $\left(\mathrm{O}_{2}\right)$, which is then degraded by GPx or by CAT to $\mathrm{H}_{2} \mathrm{O}$. Reduction in the antioxidant enzymes activities may increase the availability of $\mathrm{H}_{2} \mathrm{O}_{2}$ and $\mathrm{O}_{2}{ }^{-}$, which in turn produces hydroxyl radicals that initiate LPO [24].

In this investigation, marked decreases in the activities of SOD, CAT, and GPx enzymes were detected in the liver homogenate of $\mathrm{CCl}_{4}$ exposed animals. These findings revealed the role of $\mathrm{CCl}_{4}$ in inducing oxidative stress in the hepatic tissue. In addition, these results corroborate the observations of Manubolu et al [22] who explained that the activity of the antioxidant enzymes is decreased in tissues of $\mathrm{CCl}_{4}$-exposed rats. One probable mechanism for the decreased activities of SOD, CAT and GPx may resulted from generation of the active metabolite, trichloromethyl radical leading to oxidative stress in the tissues. Furthermore, this investigation has established that the administration of $S$. villosa extract (250 and 500 $\mathrm{mg} / \mathrm{kg}$ ) prevented the reduction in the activities of the antioxidants enzymes in liver of $\mathrm{CCl}_{4}$ exposed animals, showing a probable role of the extract in free radical inactivation and in the antioxidant defense. Therefore, the hepatoprotective effect of $S$. villosa extract could relate to its ability to preserve the antioxidant enzymes activities.

GSH is a major non-enzymatic antioxidants of the liver cells. It keeps the protein thiols of the hepatocyte membrane against the harmful effects of reactive oxygen metabolites [25]. In cases of oxidative stress, GSH is depleted and transformed to glutathione disulfide, leading to lipid peroxidation. Thus, GSH is considered as a 
significant marker for the assessment of oxidative stress [26].

In this study, the depletion of cellular GSH following $\mathrm{CCl}_{4}$ exposure leaves the cell vulnerable to oxidative stress. Pretreatment with $S$. villosa extract preserved the GSH contents in the livers of $\mathrm{CCl}_{4}$-exposed rats that further demonstrated the anti-oxidant property of this plant. The increased level of MDA is a marker for cell membrane LPO and cell damage [27]. According to Luqman and Rizvi [28], lipid peroxidation is known to injure the cells by inactivation of membrane enzymes, decrease fluidity of the membrane and resolve into cytotoxic aldehydes such as MDA. In this connection, Recknagel et al [26] stated that $\mathrm{CCl}_{4}$ is metabolically activated by CYP2E1 to trichloromethyl free radical $\left(\mathrm{CCl}_{3} \bullet\right.$ ) interacting with lipids and proteins of the cells in the presence of oxygen to induce LPO.

In this investigation, there were marked elevations in $\mathrm{LPO}$ in the homogenate of $\mathrm{CCl}_{4}$ hepatotoxic animals, as measured by MDA formation. The elevated level of hepatic MDA indicates the inability of the antioxidant defense system to protect against the production of excessive free radicals. The present results showed that $S$. villosa extract ameliorated the increased liver MDA contents of $\mathrm{CCl}_{4}$-exposed rats toward normalcy. The decreased amount of MDA in addition to the increased level of GSH in the liver of groups administered $S$. villosa extract further confirms its antioxidant capacity. In addition, hepatoprotective activity against $\mathrm{CCl}_{4^{-}}$ induced hepatic damage achieved by interfering with $\mathrm{CCl}_{4}$-mediated LPO via reduction of generation of free radicals [29] or due to the antioxidant effect of the protective agent itself [30].

The levels of TP and ALB would be reduced in cases of hepatotoxicity as a result of defective protein synthesis in the liver. Therefore, the decrease in TP and ALB levels is a further sign of hepatotoxicity in $\mathrm{CCl}_{4}$-exposed animals [31]. In this study, the levels of TP and ALB in the liver tissues were restored close to the normal values, suggesting the protective action of $S$. villosa extract. The possible mechanism behind the protective effect of $S$. villosa extract could be related to the antioxidant property of the phytoconstituents of the plant. Flavonoids, tannins, coumarins, triterpenoids and saponins are among the chemical constituents identified in plants of the genus Silene [32]. The antioxidant activity of some Silene plants has been attributed to their high levels of phenolics and flavonoids [33]. Therefore, we believe that the possible mechanism of hepatoprotection offered by $S$. villosa extract is due to its phytocomponents as phenolics, triterpenoid, saponins and flavonoids.

Histopathological observations supported the biochemical results. Histological examination of rat liver treated with $\mathrm{CCl}_{4}$ alone showed marked necrosis, neutrophil infiltration and hydropic degenerative changes of the hepatocytes that might be due to the production of free radicals by $\mathrm{CCl}_{4}$ and subsequent LPO. Pretreatment with $S$. villosa extract exhibited considerable hepatic protection in a dose-dependent pattern, which confirmed the results of biochemical studies.

\section{CONCLUSION}

The findings of the study reveal the promising anti-inflammatory and hepatoprotective potential of $S$. villosa plant in rats. The hepatoprotective effect may be mediated through its antiinflammatory and/or antioxidant actions. Accordingly, the plant extract could be developed as an effective herbal drug for protection against chemical-induced hepatic damage. Additional studies are underway to isolate the active compounds responsible for the protective effect of $S$. villosa.

\section{DECLARATIONS}

\section{Acknowledgement}

This project was supported by Support Research Groups Grant Program, Deanship of Scientific Research, Prince Sattam Bin Abdulaziz University, Al-Kharj, Kingdom of Saudi Arabia. (grant no. 2016/03/6377). The authors would like to express their gratitude to Deanship of Scientific Research of Prince Sattam bin Abdulaziz University Al-Kharj, for its assistance.

\section{Conflict of interest}

No conflict of interest is associated with this work.

\section{Contribution of authors}

We declare that this work was done by the authors named in this article and all liabilities pertaining to claims relating to the content of this article will be borne by them.

\section{REFERENCES}

1. Ahsan R, Monirul Islam KM, Musaddik A, Hague E. Hepatoprotective activity of methanol extract of some medicinal plants against carbon tetrachloride induced

Trop J Pharm Res, January 2018; 17(1): 123 
hepatotoxicity in albino rats. Glob J Pharmacol. 2009; 3(3): 116-122.

2. Nazeema TH, Brindha V. Antihepatotoxic and antioxidant defense potential of Mimosa pudica. Int J Drug Discov. 2009; 1: 1-4.

3. Sun H, Chen L, Zhou W, Hu L, Li L, Tu Q, Chang Y, Liu $Q$, Sun $X$, Wu $M$, Wang $H$. The protective role of hydrogen-rich saline in experimental liver injury in mice. J Hepatol. 2011; 54: 471-480.

4. Kamisan F, Yahya $F$, Mamat $S$, Kamarolzaman $M$, Mohtarrudin N, Kek T, Salleh M, Hussain M and Zakaria Z. Effect of methanol extract of Dicranopteris linearis against carbon tetrachloride-induced acute liver injury in rats. BMC Complemen Altern Med. 2014; 14: 123-132.

5. Ranjbar A, Sharifzadeh M, Karimi J, Tavilani H, Baeeri M, Heidary $T$, Abdollahi M. Propofol Attenuates Toxic Oxidative Stress by $\mathrm{CCl}_{4}$ in Liver Mitochondria and Blood in Rat. Iran J Pharm Res. 2014; 13(1): 253-262.

6. Weber LW, Boll M, Stampfl A. Hepatotoxicity and mechanism of action of haloalkanes: carbon tetrachloride as a toxicological model. CRC Crit Rev Toxicol. 2003; 33: 105-136.

7. Chandra S, Rawat D. Medicinal plants of the family Caryophyllaceae: a review of ethno-medicinal uses and pharmacological properties. Integr Med Res. 2015; 4: 123-131.

8. Mabberley D. The Plant-Book; Cambridge University Press: Cambridge, New York, NY, USA, 2008; $p 1040$.

9. Hirst M. Dreams and medicines: The perspective of Xhosa diviners and novices in the Eastern Cape, South Africa. Indo-Pac J Phenomenol. 2005; 5: 1-22.

10. Ahmad V, Ali Z, Ali M, Zahid M. Chemical constituents of Silene conoidea. Fitoterapia 1998; 69: 406-408.

11. Foudah A. Pharmacognostic Standardization, Phenolic and in Vitro Antioxidant Activity of Silene villosa (Family: Caryophyllaceae). Asian J Pharmaceut Res Health Care 2017; 9(3): 106-111.

12. Ghonime M, Eldomany $R$, Abdelaziz A, Soliman $H$. Evaluation of immunomodulatory effect of three herbal plants growing in Egypt. Immunopharmacol Immunotoxicol. 2011; 33: 141-145.

13. Guide for the care and use of laboratory animals, Committee for the Update of the Guide for the Care and Use of Laboratory Animals, Institute for Laboratory Animal Research, 8th Ed, (2011).

14. OECD. Guidelines number 425 for testing chemicals. Acute oral toxicity-up and down procedure, 2001; pp. 12-16.

15. Winter C, Risley E, Nuss G. Carrageenan-induced oedema in the hind paw of rat as an assay for antiinflammatory activity. Proc Soc Exp Biol Ther. 1962; 111: 544-547.

16. Kennedy GL, Ferenz RL, Burgess BA. Estimation of acute oral toxicity in rats by determination of the approximate lethal dose rather than the LD50. J Applied Toxicol. 1986; 6: 145-148.

17. Kuedo Z, Sangsuriyawong A, Klaypradit W, Varomyalin Tipmanee $V$, Chonpathompikunlert $P$. Effects of
Astaxanthin from Litopenaeus Vannamei on Carrageenan-Induced Edema and Pain Behavior in Mice. Molecules 2016; 21: 382-395.

18. Umukoro S, Ashorobi R. Evaluation of anti-inflammatory and membrane stabilizing property of aqueous leaf extract of Momordica charantia in rats. Afr $J$ Biomed Res. 2006; 9: 119 -124.

19. Khan RA, Khan MR, Ahmed M, Sahreen S, Shah NA, Shah MS, Bokhari J, Rashid U, Ahmad B, Jan S. Hepatoprotection with a chloroform extract of Launaea procumbens against $\mathrm{CCl}_{4}$-induced injuries in rats. BMC Complemen Altern Med. 2012; 12: 114.

20. Pachathundikandi S, Varghese E. Blood zinc protoporphyrin, serum total protein, and total cholesterol levels in automobile workshop workers in relation to lead toxicity: Our experience Indian J Clin Biochem. 2006; 21(2): 114-117.

21. Ogeturk M, Kus I, Kavakli A, Zararsiz I, Ilhan N, Sarsilmaz $M$. Effects of melatonin on carbon tetrachloride-induced changes in rat serum. J Physiol Biochem. 2004; 60 (3): 205-210.

22. Manubolu M, Goodla L, Ravilla S, Thanasekaran J, Dutta $P$, Malmlöf K, Obulum VR. Protective effect of Actiniopteris radiata (Sw.) Link. against $\mathrm{CCl}_{4}$ induced oxidative stress in albino rats. J. Ethnopharmacol. 2014; 153: 744-752.

23. Stoyanovsky D, Cederbaum A. Metabolism of carbon tetrachloride to trichloromethyl radical: an ESR and HPLC-EC study. Chem Res Toxicol. 1999; 12: 730-736.

24. Kinalski $M$, Sledziewski A, Telejko B, Zarzycki W, Kinalska I. Lipid peroxidation and scavenging enzyme activity in streptozotocin-induced diabetes, Acta Diabetol. 2000; 37: 179-183.

25. Meister A. Glutathione, ascorbate, and cellular protection. Cancer Res. 1994; 54 (7): 1969s-1975s.

26. Recknagel R, Glonde E, Dolak J. Walter R. Mechanism of carbon tetrachloride toxicity. Pharmacol Ther. 1989; 43: $139-154$

27. Babu BH, Shylesh BS, Padikkala J. Antioxidant and Hepatoprotective effect of Acanthus ilicifolius. Fitoterapia 2001; 72: 272-277.

28. Luqman S, Rizvi S. Protection of Lipid Peroxidation and Carbonyl Formation in Proteins by Capsaicin in Human Erythrocytes Subjected to Oxidative Stress Phytother Res. 2006; 20(4):303-6.

29. Castro JA, de Ferreyra GC, de Castro CR, Sesame H, de Fenos OM, Gillette JR. Prevention of carbon tetra chloride induced necrosis by inhibitors of drug metabolism. Further studies on the metabolism of their action. Biochem Pharmacol. 1974; 23: 295-302.

30. Yasuda H, Izugami N, Shimadar O, Koba Yakawa $Y$, Nakanishi $M$. The protective effect of tinoride against carbon tetrachloride hepatotoxicity. Toxicol Appl Pharm. 1980; 52: 4207-4213.

31. Alam MN, Bristi NJ, Rafiquzzaman M. Review on in vivo and in vitro methods evaluation of antioxidant activity. Saudi Pharm J. 2013; 21: 143-152.

Trop J Pharm Res, January 2018; 17(1): 124 
Yusufoglu et al

32. Boukhira S, Mansouri L, Bouarfa M, Ouhammou A, Achour S, Khadr $M$ and Bousta D. Phytochemical screening, anti-inflammatory and analgesic activities of formulation cream of silene vulgaris. Res $J$ Med Plant 2016; 10(2): 150-158.
33. Karamian R, Ghasemlou F. Screening of total phenol and flavonoid content, antioxidant, and antibacterial activities of the methanolic extracts of three Silene species from Iran. Intl J Agri Crop Sci. 2013; 5: 305-312. 